kambodschanisches Ersuchen vom 25. Juni 1966, das sich nur auf die Verstärkung der Internationalen Kontrollkommission an dieser Grenze bezog, ist durch die Sowjetunion in ihrer Eigenschaft als Ko-Vorsitzende der Genfer IndochinaKonferenz torpediert worden. Schon im Vorjahr haben die Vietcong auf der in Kambodscha tagenden Konferenz der Völker Indochinas Norodom Sihanuk daran gehindert, seine Forderung nach Neutralisierung Kambodschas in einer Rede vorzutragen $^{29}$. Denn seit 1965 kommt der Hauptwiderstand gegen eine internationale Konferenz zur Neutralisierung Kambodschas und zur Garantie seiner gegenwärtigen Grenzen nicht mehr von amerikanischer, sondern von kommunistischer Seite - eine unmittelbare Folge des Vietnam-Krieges. Wegen der militärischen Situation in seinem Nachbarland und der sich daraus ergebenden politischen Aussichten sieht sich Kambodscha auch nicht mehr in der Lage, einer solchen Konferenz unter nicht-kommunistischen Bedingungen zuzustimmen: Bereits am 1. Mai 1965 war Kambodscha gezwungen, einen entsprechenden britischen Gegenvorschlag abzulehnen und den Ausschluß der Regierung Südvietnams von einer solchen Konferenz zu verlangen. Wenn schon die Auflösung Südvietnams, das Kambodscha von der nordvietnamesischen Übermacht trennt, den Spielraum der Außenpolitik Sihanuks so einschränkt, ist es ziemlich offensichtlich, was die Konsolidierung eines von den Kommunisten geeinten Vietnam für Kambodscha bedeuten würde. So hat der kambodschanische Regierungschef in einem privaten Gespräch mit dem Chefminister von Sarawak 1966 ganz offen erklärt, daß er es vorziehen würde, wenn Vietnam weiterhin geteilt bliebe. Dabei macht Norodom Sihanuk keinen Unterschied zwischen einem kommunistischen oder einem nicht-kommunistischen Vietnam, als er sagte: „Ob er Kaiser Gia Long, Ho Chi Minh oder Ngo Dinh Diem heißt, kein Vietnamese wird friedlich ruhen können, bis er Kambodscha in die Vernichtung getrieben hat, nicht ohne es vorher durch das Stadium der Sklaverei getrieben zu haben. "30 Gerade im Hinblick auf den sich inzwischen abzeichnenden Ausgang des Vietnam-Krieges müssen die Worte von Norodom Sihanuk (in einem Interview mit der Ceteka - Tschechoslowakischen Telegraphenagentur - vom Jahre 1960) über Kambodschas Haltung zum kommunistischen Nordvietnam zitiert werden: „... Man kann nicht wirklich die Aufrichtigkeit oder den Pazifismus eines Staates beurteilen, bis seine Grenzen sich mit den eigenen berühren ..." ${ }^{31}$

\title{
Anmerkung der Redaktion
}

Die Zeitschrift will nicht nur analysieren, sondern zugleich auch über die wichtigsten Entwicklungen informieren. Da der Verfasser des vorstehenden Aufsatzes sich seit 1968 zu Studien am East-West Centre von Hawaii aufhält, war es ihm nicht mehr möglich, die jüngste Entwicklung der kambodschanischen Außenpolitik in sein Manuskript einzuarbeiten. Die Redaktion hat daher Herrn Dr. M. Y. Cho um die folgende Darstellung gebeten.

Die jüngste Entwicklung der kambodschanischen Außenpolitik:

In Anbetracht der Möglichkeit eines absehbaren Endes des Vietnam-Krieges, die seit 1967 erkennbar wurde, versuchte Sihanuk, auch das Verhältnis zu Nordvietnam $\mathrm{zu}$ verbessern. In jüngster Zeit scheint er ein Gleichgewichtssystem mit drei rivalisierenden Staaten zu erstreben: China gegen Vietnam und die USA, die USA gegen Vietnam und China, Vietnam gegen China und die USA ${ }^{32}$. Schon unmittelbar

29 Cambodge, Ministère d'Information, Discourse de Norodom Sihanouk Upayuvareach, Chef de l'Etat du Cambodge, a l'occasion de l'ouverture de la Conférence des peuples indochinoises, Phnom Penh, 25.2. 1965.

30 Kambuja, 1. 4. 1966, S. 26, zitiert bei Leifer, S. 188; Cambodia News, Januar 1963, S. 4; Phnom Penh Presse, 24. 6. 1966.

31 Royaume du Cambodge, Principaux discours ... de ... Norodom Sihanuk en 1960, o. O. (Phnom Penh?) u. J., S. 166

32 Als Quellen für die jüngste Entwicklung wurden herangezogen: Asahi Nenkan ("Asahi-Jahrbuch“), 1967 und 1968, Tokio; Europa-Archiv; Summary of World Broadcasts (BBC), London; Far Eastern Economic Review, Hongkong; Realités Cambodgiénnes, Phnom Penh; Le Monde, Paris. 
nach dem Staatsbesuch de Gaulles in Kambodscha forderte Sihanuk auf einer Kundgebung am 4. September 1966 die USA auf, die gegenwärtigen Grenzen Kambodschas anzuerkennen. Sobald Washington diese Anerkennung ausgesprochen habe, werde Kambodscha bereit sein, seine Beziehungen zu den USA wieder zu normalisieren. Am 3. April 1967 erklärte Prinz Sihanuk, daß seit dem Ausbruch einer von Kommunisten getragenen Rebellion in der Westprovinz Battambang sein Land nicht mehr nur der Aggressionsgefahr durch die amerikanischen und südvietnamesischen Truppen, sondern auch „einer dritten Gefahr" gegenüberstehe; ob diese Gefahr von China oder Nordvietnam gefördert würde, ließ er dabei offen. Er fügte allerdings hinzu, daß er trotzdem keine ausländische Hilfe benötige und auch seine Neutralitätspolitik weiterhin fortsetzen werde. Am 2. Mai 1967 gab er die Bildung eines Notstandskabinetts unter seinem Vorsitz bekannt. In einer Pressekonferenz am 8. Juni 1967 bezeichnete Sihanuk dann die Nationale Befreiungsfront Südvietnams als legitimen Vertreter des südvietnamesischen Volkes. Danach teilte er am 13. Juni mit, Nordvietnam und die Nationale Befreiungsfront hätten die Unverletzlichkeit der kambodschanischen Grenzen garantiert. Zwei Tage später anerkannte Kambodscha völkerrechtlich die Demokratische Republik Vietnam. Am 1. September gab der Prinz bekannt, Kambodscha werde die diplomatischen Beziehungen $\mathrm{zu}$ allen Staaten, die seine Grenzen nicht anerkennen, durch die Abberufung der Botschafter "abkühlen“ lassen. Betroffen werden sollten davon vor allem Japan, Großbritannien, Australien und die Philippinen. Andererseits drohte am 13. September der kambodschanische Staatschef mit der Abberufung seines Botschafters aus Peking als Protest gegen den Export der chinesischen Kulturrevolution nach Kambodscha. Es gehe nicht an, daß China Kambodscha das Recht bestreite, Herr im eigenen Haus zu sein. Sein Land wolle zwar mit China befreundet bleiben, werde es aber niemals zulassen, daß es ein "Satellit“ Pekings wird. Gleichzeitig machte sich wieder ein Annäherungsversuch Sihanuks gegenüber den USA bemerkbar, obschon er nach wie vor das amerikanische Eingreifen in Vietnam scharf verurteilte und der Regierung in Hanoi politische und moralische Unterstützung zusagte. So bot Sihanuk auf einer Pressekonferenz am 4. November 1967 den USA die Wiederaufnahme der diplomatischen Beziehungen an, und zwar unter der Voraussetzung, daß sie die Grenzen Kambodschas künftig respektieren. Auf derselben Konferenz sagte er auch, daß Asien „früher oder später chinesisch“ sein werde, daß er selber sich aber "niemals den Chinesen" beugen werde. Am 27. November sagte er dann wieder, man müsse künftig mit Bombardierungen großen Ausmaßes oder gar der Besetzung eines Teiles seines Landes durch amerikanische Truppen rechnen; er schlug daher vor, die Internationale Kontrollkommission für Vietnam zu verstärken und mit der Überwachung der Neutralität Kambodschas $\mathrm{zu}$ beauftragen. Kambodscha werde, so erklärte Sihanuk am 26. Dezember, im Falle einer „Aggression größeren Ausmaßes“ nicht zögern, China und die UdSSR um militärische Hilfe zu ersuchen.

Vom 8. bis 12. Januar 1968 fanden in Phnom Penh Besprechungen zwischen dem amerikanischen Botschafter in Indien, Chester Bowles, und der kambodschanischen Regierung statt. In einem Kommuniqué wurde mitgeteilt, daß sich beide Seiten für eine Stärkung der Internationalen Kontrollkommission zur Überwachung der kambodschanischen Grenzen ausgesprochen hätten. Sihanuk erklärte, beide Seiten hätten sich darauf geeinigt, nach Beendigung des Vietnam-Krieges die kambodschanisch-amerikanischen Beziehungen zu normalisieren. Aber schon am 12. Februar protestierte die kambodschanische Regierung beim Sicherheitsrat der Vereinten Nationen über eine Reihe "barbarischer Angriffe" südvietnamesischer und amerikanischer Truppen über die kambodschanische Landesgrenze hinweg.

Staatschef Prinz Norodom Sihanuk erklärte am 8. August 1968 erneut, sein Land werde die Hilfe Nordvietnams und der Volksrepublik China in Anspruch nehmen, falls die „ernste Bedrohung“ der an Vietnam angrenzenden kambodschanischen Provinz Svay Rieng durch US-Streitkräfte anhielte. Anfang November 1968 bat 
er die USA, in Verfolg der Pariser Vietnam-Friedensgespräche nicht Südostasien zu verlassen und ein kommunistisch wiedervereinigtes Vietnam zu hinterlassen, da nur die USA ein wirksames Gegengewicht gegen China in diesem Gebiet und eine Sicherheit für sein Land darstellen könnten. Aber in den Vereinten Nationen zählte auch in diesem Jahr Kambodscha zu den 16 Ländern, die am 19. November die Resolution für die Aufnahme Pekings einbrachten. Gleichzeitig schickte Sihanuk ein Telegramm an Ho Chi-minh, in dem es u. a. hieß: „Zusammen mit dem kambodschanischen Volk schätze ich mich glücklich, Sie und alle vietnamesischen Brüder erneut unserer Solidarität und unserer Unterstützung der gerechten Haltung der Demokratischen Republik Vietnam und der Nationalen Befreiungsfront in der Frage der Einstellung der USA-Aggression, des Abzuges der amerikanischen Truppen aus Südvietnam und der Einstellung der amerikanischen Einmischung in die inneren Angelegenheiten Vietnams zu versichern ... Wir erklären erneut, daß wir das politische Programm der Nationalen Befreiungsfront als die einzige vernünftige Grundlage für die Wiederherstellung des Friedens in Südvietnam unterstützen." Ende November bat Sihanuk den Generalsekretär der Vereinten Nationen, U Thant, „die US-Regierung zu zwingen, sofort das Töten der kambodschanischen Zivilbevölkerung an der Landesgrenze einzustellen“. Am 10. Januar 1969 hat Sihanuk in einer Rede in Gegenwart des chinesischen Geschäftsträgers in Pnom Penh ausgeführt, daß Kambodscha stets in erster Linie mit China, in weiterer Linie mit Frankreich und in dritter Linie mit der Sowjetunion Freundschaft pflegen werde. Wortwörtlich sagte der Prinz ferner: "Wir werden niemals Feinde Chinas werden und wir werden in den kommenden zehn Generationen auf keinen Fall streiten ...."

In der Regierungserklärung vom 3. Februar 1969 sagte Sihanuk, daß der Frieden in Vietnam nicht anders hergestellt werden kann als durch den bedingungslosen Abzug der amerikanischen Truppen aus Südvietnam und die „Anerkennung des heiligen Rechts des vietnamesischen Volkes, über seine Belange ohne ausländische Intervention oder Einmischung zu entscheiden".

Gerade die jüngste Entwicklung gleicht einem schnell rotierenden Karussell des Werbens und Anschuldigens. Das hat Sihanuk schon den Vorwurf eingebracht, launenhafte Politik zu treiben. Aber Sihanuk hält sich nicht für "launenhaft" („mercuriel“), sondern er meint, die Entwicklungen in der Weltpolitik seien „launenhaft“, er reagiere nur auf sie aus dem nationalen Interesse Kambodschas.

M. Y.C. 